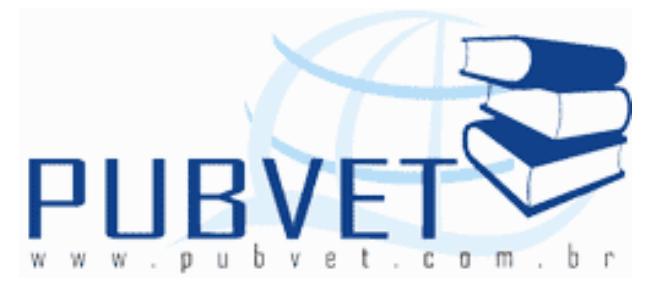

PUBVET, Publicações em Medicina Veterinária e Zootecnia.

\title{
Estudo anatômico comparativo do tubo digestório de aves da ordem Columbiformes
}

\author{
André Luiz Quagliatto Santos ${ }^{1}$, Mariana Batista Andrade ${ }^{3}$, Lorena Tannús \\ Menezes $^{2}$, Rogério Rodrigues de Souza ${ }^{2}$, Caio Henrique Ferreira ${ }^{2}$, Sérgio \\ Rodrigo Pereira de Oliveira ${ }^{2}$, Árthur Paulino Sanzo Kaminishi ${ }^{2}$, Liliane Rangel \\ Nascimento ${ }^{2}$, Flávio Machado de Moraes ${ }^{1}$
}

Laboratório de Ensino e Pesquisa em Animais Silvestres - LAPAS, FAMEV/UFU, e-mail: quagliatto@famev.ufu.br 1. Docente. 2. Mestrandos. 3. Doutoranda.

\section{Resumo}

Cerca de 9800 espécies pertencentes à classe das Aves atualmente, inúmeras vem sendo criadas como animais de estimação ou mantidas em cativeiro, fato que desperta a necessidade por maiores conhecimentos de ordem anatômica e fisiológica nestes animais. A capacidade evolutiva do tubo digestório permitiu a sobrevivência das diversas populações de aves atuais, que criaram seus nichos ecológicos próprios de acordo com os recursos alimentares disponíveis. O interesse foi realizar uma descrição anatômica comparativa do tubo digestório de aves da ordem Columbiformes, com quatro exemplares de aves, Zenaida auriculata, Columba Lívia, Patagioenas picazuro, doadas pelo IBAMA Uberlândia-MG para o Laboratório de Ensino e Pesquisa em Animais Silvestres (LAPAS) da Faculdade de Medicina Veterinária da UFU, onde foram fotografados, identificadas quanto à espécie e dissecadas, com a finalidade de 
SANTOS, A.L.Q. et al. Estudo anatômico comparativo do tubo digestório de aves da ordem Columbiformes. PUBVET, Londrina, V. 6, N. 10, Ed. 197, Art. 1323, 2012.

se obter informações relativas à topografia, forma e dimensões dos segmentos do tubo digestório. As espécies estudadas apresentam inglúvio e cecos, e o tubo digestório possui poucas variações topográficas entre elas.

Palavras-chave: pombos, esôfago, estômago, intestino.

\title{
Comparative anatomical study of the digestive tract of avians of Columbiforms order
}

\begin{abstract}
About 9800 species of birds belonging to the avians class now a day, many are being raised as pets or kept in captivity, a fact which raises the need for more knowledge of anatomical and physiological order in these animals. The evolving capacities of the digestive tract allow the survival of many populations of avians presents, which created their own niche according available food resources. The interest was conduct a comparative anatomical description of the digestive tract of avians of the Columbiforms order, with four specimens of birds, Zenaida auriculata, Columba Livia, Patagioenas picazuro, donated by IBAMA, Uberlândia / MG. In the Laboratório de Ensino e Pesquisa em Animais Silvestres (LAPAS) UFU, the birds were photographed and identified as to species and dissected for the purpose of obtaining information on topography, form and dimensions of the segments of the digestive tract. All the studied specimens have cecum and ingluvium, and the digestive tract showed little topographical variations.
\end{abstract}

Keywords: pigeons, esophagus, stomach, intestine.

\section{INTRODUÇÃO}

Atualmente, estão descritas cerca de 9800 espécies pertencentes à classe das Aves, divididas em 28 ordens (PERRINS, 2004), sendo que a maior ordem é a dos Passeriformes, com 5712 espécies, e a menor a dos Struthioniformes, representada pelas emas e avestruz (KING e McLELLAND, 1984). 
SANTOS, A.L.Q. et al. Estudo anatômico comparativo do tubo digestório de aves da ordem Columbiformes. PUBVET, Londrina, V. 6, N. 10, Ed. 197, Art. 1323, 2012.

O aparelho digestório é o tubo adaptado para processar e utilizar o mais eficientemente possível o alimento disponível em seu habitat (DUKES, 1996; POUGH; HEISER; McFARLAND, 1999). Essa capacidade evolutiva permitiu a sobrevivência das diversas populações de aves atuais, que criaram seus nichos ecológicos próprios de acordo com os recursos alimentares disponíveis (PETERSON et al., 1971).

As aves possuem o tubo digestório composto por esôfago, estômagos, intestino delgado e intestino grosso (GETTY, 1986).

Segundo Duke (1996), o volume e o comprimento do trato digestório variam consideravelmente entre as espécies, dependendo, sobretudo dos hábitos alimentares. Aves carnívoras e piscívoras precisam expandir as áreas de estocagem para acomodar grande volume de alimento mole. Já as que comem insetos ou sementes precisam de um órgão muscular responsável pela trituração do alimento (POUGH; HEISER; McFARLAND, 1999). Pássaros frugívoros como os gaturamos, não possuem o estômago muscular, presente nas demais aves (SICK, 1997).

A função da anatomia topográfica como método auxiliar na clínica e cirurgia foi citado por Dukes (1996), que enfatizou o esôfago e o papo são freqüentemente acometidos por corpos estranhos e impactação. Ainda segundo este autor, por serem palpáveis devido à sua localização subcutânea, possuem fácil acesso cirúrgico.

O objetivo do presente estudo foi realizar uma descrição anatômica comparativa do tubo digestório de aves da ordem Columbiformes, enfocando as principais características topográficas e particularidades anatômicas dos representantes.

\section{MATERIAL E MÉTODOS}

Este estudo foi realizado utilizando-se quatro aves de diferentes espécies doadas pelo IBAMA - Uberlândia-MG para o Laboratório de Ensino e Pesquisa em Animais Silvestres (LAPAS) da Faculdade de Medicina Veterinária da 
SANTOS, A.L.Q. et al. Estudo anatômico comparativo do tubo digestório de aves da ordem Columbiformes. PUBVET, Londrina, V. 6, N. 10, Ed. 197, Art. 1323, 2012.

Universidade Federal de Uberlândia, onde foram fotografados, de modo a enfatizar aspectos individuais que diferenciam as espécies.

A identificação das aves incluiu sua classificação quanto à ordem, família, gênero e espécie e foi realizada com auxílio da Lista das aves do Brasil (2011).

As espécies da ordem Columbiformes estudadas foram um exemplar de Zenaida auriculata Des Murs, 1847 (pomba-de-bando), dois exemplares de Columba Lívia Gmelin, 1789 (pombo-doméstico) e um exemplar de Patagioenas picazuro Temminck, 1813 (pombão) (Figuras 1, 2 e 3).

Cada exemplar, depois de submetido ao processo completo de dissecação e registro das informações relevantes, foi conservado em solução de formaldeído a $10 \%$ injetada em toda a musculatura das aves com seringas descartáveis de 1,5 ou $10 \mathrm{ml}$ e agulha hipodérmica $30-8$ ou agulha descartável de $13 \times 0,45 \mathrm{~mm}$.

Cada ave foi dissecada a fresco, com a finalidade de manter os órgãos em suas dimensões originais, obtendo-se medidas de comprimento e diâmetro com mínima margem de erro. Concomitantemente, procedeu-se à descrição e elaboração de desenhos esquemáticos (figuras 4) e fotografias (figuras 1, 2, 3 e 5) enfocando características relativas a dimensionamento, topografia, morfologia e composição do tubo digestivo.

O comprimento total de cada ave, que consiste na distância entre a extremidade rostral do bico até a extremidade caudal da última pena da cauda, foi obtido com o animal em decúbito dorsal e com o pescoço estendido. A pomba-de-bando (Zenaida auriculata), macho, apresentou 23,40 cm de comprimento, o pombo-doméstico (Columba Lívia), machos, apresentaram $35,75 \mathrm{~cm}$ de comprimento (Figuras 1, 4 e 5), e o pombão (Patagioenas picazuro), macho, apresentou $35,17 \mathrm{~cm}$ de comprimento. 
SANTOS, A.L.Q. et al. Estudo anatômico comparativo do tubo digestório de aves da ordem Columbiformes. PUBVET, Londrina, V. 6, N. 10, Ed. 197, Art. 1323, 2012.

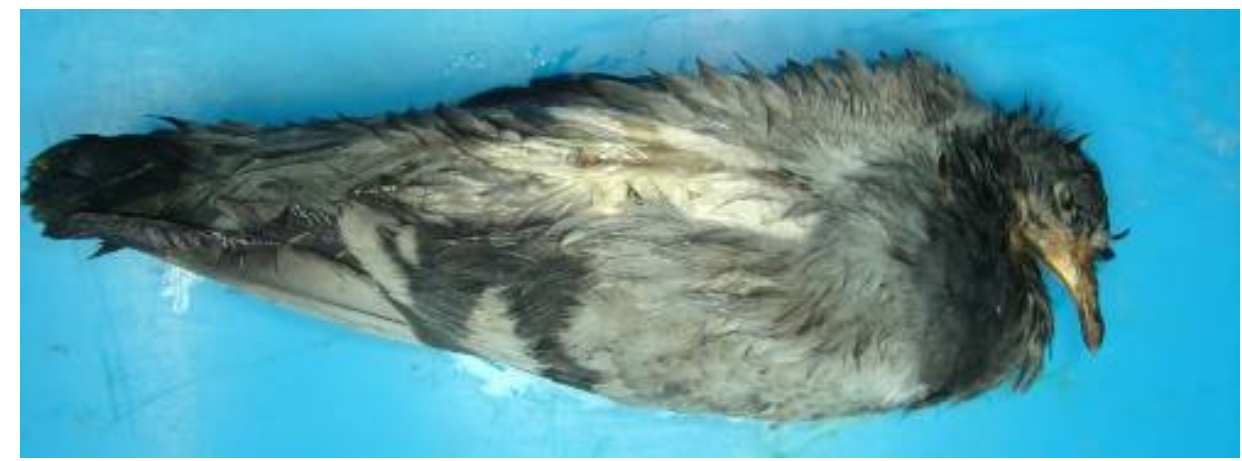

Figura 1: Pombo-doméstico Columba lívia Gmelin, 1789 (COLUMBIDAE)

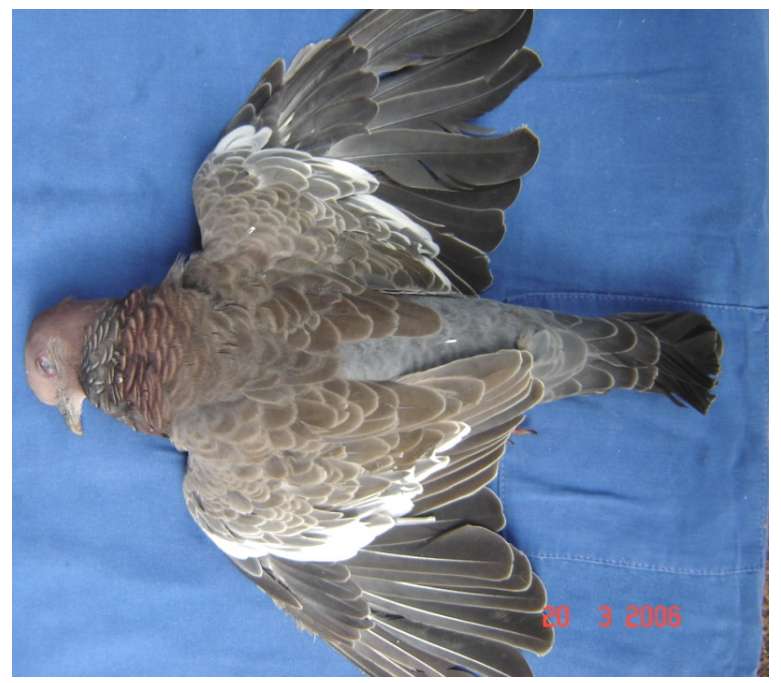

Figura 2: Pombão Patagioenas picazuro Temminck, 1813 (COLUMBIDAE)

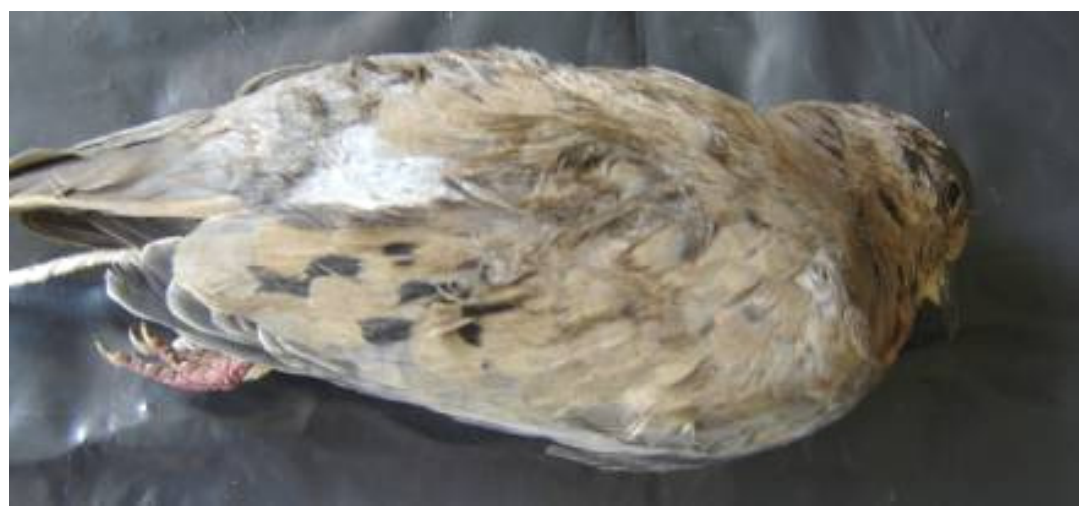

Figura 3: Pomba-do-bando Zenaida auriculata Des Murs, 1847 (COLUMBIDAE). 
SANTOS, A.L.Q. et al. Estudo anatômico comparativo do tubo digestório de aves da ordem Columbiformes. PUBVET, Londrina, V. 6, N. 10, Ed. 197, Art. 1323, 2012.

Com o auxílio de um cabo de bisturi no 4, uma lâmina para bisturi no 23, uma pinça Adson e uma pinça anatômica, procedeu-se a abertura da cavidade toracoabdominal de cada exemplar a partir de uma incisão na linha mediana ventral (delimitada pelo osso esterno e cloaca) e posterior retirada da quilha.

Foram adotados os seguintes pontos de referência para descrição anatômica e mensuração dos segmentos do tubo digestivo:

Esôfago cervical: início na laringe e término na entrada da cavidade tóracoabdominal;

Inglúvio: início na região de dilatação do esôfago cervical e término na extremidade cranial do esôfago torácico;

Esôfago torácico: início na entrada da cavidade e término na junção com o proventrículo;

Proventrículo: início na união com esôfago torácico e término na divisão com o ventrículo ou no istmo, quando presente;

Ventrículo: início na união com o proventrículo e término no início da alça descendente do duodeno;

Alça descendente do duodeno: início no piloro e término na curvatura de união com a alça ascendente do duodeno;

Alça ascendente do duodeno: início na união com a alça anterior e término na curvatura de união ao segmento jejunoilíaco;

Jejuno-íleo: início na união com o segmento anterior e término na divisão com coloreto, considerando-se a presença de cecos, quando existirem;

Ceco(s): do seu ponto de inserção no segmento intestinal ao seu ápice;

Coloreto: início na base do(s) ceco(s), quando existirem ou do momento em que se desfazem as alças que compõem o segmento jejunoilíaco e término na cloaca;

Após descrição topográfica, o tubo digestivo foi individualizado com o auxílio de uma pinça anatômica, uma pinça hemostática, uma pinça dente de rato, uma tesoura Mayo curva e uma tesoura Metzembaum reta, divulsionando-se os tecidos que mantinham os segmentos do tubo digestivo relacionado a outros órgãos. 
SANTOS, A.L.Q. et al. Estudo anatômico comparativo do tubo digestório de aves da ordem Columbiformes. PUBVET, Londrina, V. 6, N. 10, Ed. 197, Art. 1323, 2012.

Cada órgão foi mensurado com um paquímetro Starret de precisão 0,05 $\mathrm{mm}$, de modo a registrar o comprimento e diâmetro dos mesmos. As medidas de diâmetro tomadas não se apresentam de maneira constante para todas as aves, uma vez que variaram de acordo com o estado de distensão do órgão no momento do óbito da ave.

Estabeleceu-se uma relação, em porcentagem média, entre o comprimento de cada segmento do tubo digestivo e o comprimento total dos exemplares. (Quadros 1, 2 e 3).

\section{RESULTADOS}

Quadro 1: Medidas de comprimento e diâmetro dos órgãos do tubo digestivo de pombo-doméstico, no 41

\begin{tabular}{|l|c|c|}
\hline Órgão & Comprimento (mm) & Diâmetro (mm) \\
\hline Esôfago cervical & 94,20 & 14,60 \\
\hline Esôfago torácico & 47,80 & 3,70 \\
\hline Inglúvio & 37,85 & 35,90 \\
\hline Proventrículo & 17,00 & 8,75 \\
\hline Ventrículo & $25,20 \times 27,85 \times 15,40$ \\
\hline $\begin{array}{l}\text { Alça descendente do } \\
\text { duodeno }\end{array}$ & 50,35 & 5,15 \\
\hline $\begin{array}{l}\text { Alça ascendente do } \\
\text { duodeno }\end{array}$ & 54,60 & 6,25 \\
\hline Jejuno-íleo & 417,10 & 5,10 \\
\hline Ceco direito & 5,15 & 1,70 \\
\hline Ceco esquerdo & 4,30 & 0,85 \\
\hline Coloreto & 28,10 & 5,00 \\
\hline Comprimento X Largura X Espessura & \\
\hline
\end{tabular}


SANTOS, A.L.Q. et al. Estudo anatômico comparativo do tubo digestório de aves da ordem Columbiformes. PUBVET, Londrina, V. 6, N. 10, Ed. 197, Art. 1323, 2012.

Quadro 2: Medidas de comprimento e diâmetro dos órgãos do tubo digestivo de pombão, no 04

\begin{tabular}{|l|l|l|}
\hline Órgão & Comprimento $\mathbf{( m m )}$ & Diâmetro (mm) \\
\hline Esôfago cervical & 82,20 & 10,50 \\
\hline Esôfago torácico & 38,65 & 9,00 \\
\hline Inglúvio & 29,70 & 29,10 \\
\hline Proventrículo & 30,90 & 9,60 \\
\hline Ventrículo & $20,30 \times 25,75 \times 14,90$ & \multicolumn{2}{|l|}{} \\
\hline Alça descendente do duodeno & 53,90 & 5,95 \\
\hline Alça ascendente do duodeno & 64,20 & 6,85 \\
\hline Jejuno-íleo & 400,00 & 5,00 \\
\hline Ceco direito & 4,50 & 2,00 \\
\hline Ceco esquerdo & 4,00 & 1,65 \\
\hline Coloreto & 19,00 & 5,65 \\
\hline
\end{tabular}

- Comprimento X Largura X Espessura

Quadro 3: Medidas de comprimento e diâmetro, dos órgãos do tubo digestivo de pomba-do-bando, no 05

\begin{tabular}{|l|c|l|}
\hline Órgão & Comprimento (mm) & Diâmetro (mm) \\
\hline Esôfago cervical & 40,65 & 8,15 \\
\hline Esôfago torácico & 26,05 & 3,70 \\
\hline Inglúvio & 17,25 & 26,65 \\
\hline Proventrículo & 19,20 & 5,00 \\
\hline Ventrículo & $25,40 \times 16,40 \times 12,40$ \\
\hline Alça descendente do duodeno & 25,15 & 3,95 \\
\hline Alça ascendente do duodeno & 25,00 & 3,75 \\
\hline Jejuno-íleo & 279,75 & 3,05 \\
\hline Ceco (esquerdo) & 4,35 & 3,30 \\
\hline Coloreto & 32,20 & 4,10 \\
\hline
\end{tabular}


SANTOS, A.L.Q. et al. Estudo anatômico comparativo do tubo digestório de aves da ordem Columbiformes. PUBVET, Londrina, V. 6, N. 10, Ed. 197, Art. 1323, 2012.

O esôfago cervical inicia-se na face ventral do pescoço, dorsalmente à traquéia e segue sua trajetória pelo lado direito do pescoço, antagonicamente à mesma. Equivale em média a $22,26 \%$. No terço caudal do pescoço se dilata, formando o inglúvio que se apresenta como uma grande bolsa arredondada e representa em média $8,79 \%$ do comprimento total das aves estudadas (Figura 4).

O esôfago torácico segue pelo lado direito da cavidade, lateralmente à traquéia, dorsalmente à siringe, bifurcação traqueal, base do coração e ventralmente aos pulmões. Une-se ao proventrículo à nível da metade caudal do coração e dos pulmões e equivale em média, a $11,82 \%$ do comprimento total dos representantes (Figura 4).

O estômago químico é cilíndrico, idêntico ao esôfago em formato e diâmetro, o que impossibilita uma diferenciação externa entre os dois segmentos. A divisão é visível através da visualização da superfície interna do proventrículo, que é mais espessa e repleta de pequenas elevações, em contraste à do esôfago, que possui parede lisa. Situa-se ventralmente à metade caudal do lobo pulmonar esquerdo e parte do testículo esquerdo.

O ventrículo possui formato de lente biconvexa, posiciona-se no antímero esquerdo da cavidade, ocupando grande parte do quadrante caudal. Relacionase ao terço caudal do lobo hepático esquerdo através de sua face cranioventral. Está situado ventralmente ao lobo renal caudal esquerdo, duodeno, jejuno-íleo e coloreto. Sua face ventrolateral direita relaciona-se à face dorsomedial do lobo hepático direito, em toda sua extensão. Equivale em média, a 7,88\% do comprimento total dos representantes.

O duodeno está localizado ventralmente às alças jejunoilíacas, lateralmente ao coloreto e, em praticamente toda sua extensão, dorsalmente ao lobo hepático direito, ao qual se une por mesentério.

Tem início na face dorsal do ventrículo em pombo-doméstico e pombão na face lateral direita do mesmo em pomba-do-bando, através da alça descendente do duodeno. Esta segue caudalmente pelo antímero direito até a porção final da cloaca onde se une à alça ascendente do duodeno através de 
SANTOS, A.L.Q. et al. Estudo anatômico comparativo do tubo digestório de aves da ordem Columbiformes. PUBVET, Londrina, V. 6, N. 10, Ed. 197, Art. 1323, 2012.

uma curva em sentido cranial. Representa em média, 13,38\% do comprimento total das aves.

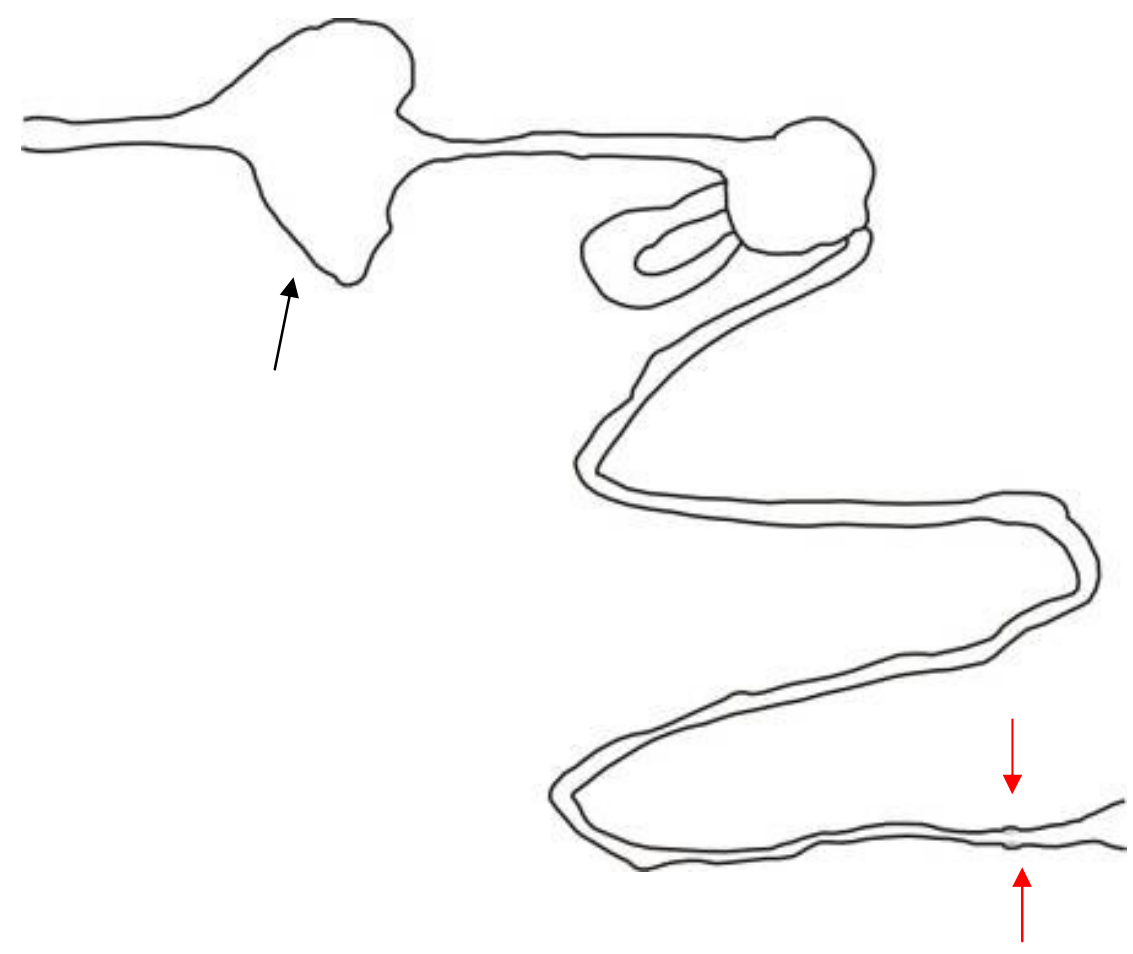

Figura 4: Representação esquemática do tubo digestório de pombodoméstico. Inglúvio (seta preta) e dois cecos (setas vermelhas).

A alça ascendente do duodeno faz a trajetória oposta e lateralmente à porção descendente, unindo-se ao segmento jejunoilíaco ventralmente ao lobo renal cranial direito, à nível da metade cranial do lobo hepático direito. Equivale em média, a $14,73 \%$ do comprimento total dos representantes.

O jejuno-íleo dispõe-se em alças, ao longo do terço caudal da cavidade. Situa-se predominantemente no antímero direito, dorsalmente ao testículo e rim e representa em média $116,65 \%$ do comprimento total das aves estudadas.

A divisão entre intestino grosso e intestino delgado é marcada por um pequeno par de cecos, de formato cilíndrico, diâmetro uniforme, direcionados cranialmente e posicionados em faces opostas do segmento intestinal. Os 
cecos direito e esquerdo equivalem em média a $1,35 \%$ e $1,39 \%$ do comprimento total dos representantes.

O coloreto tem início à nível da extremidade caudal lobo renal cranial esquerdo, segue ventralmente ao rim, até a cloaca. Representa em média, $9,06 \%$ do comprimento total das aves estudadas.

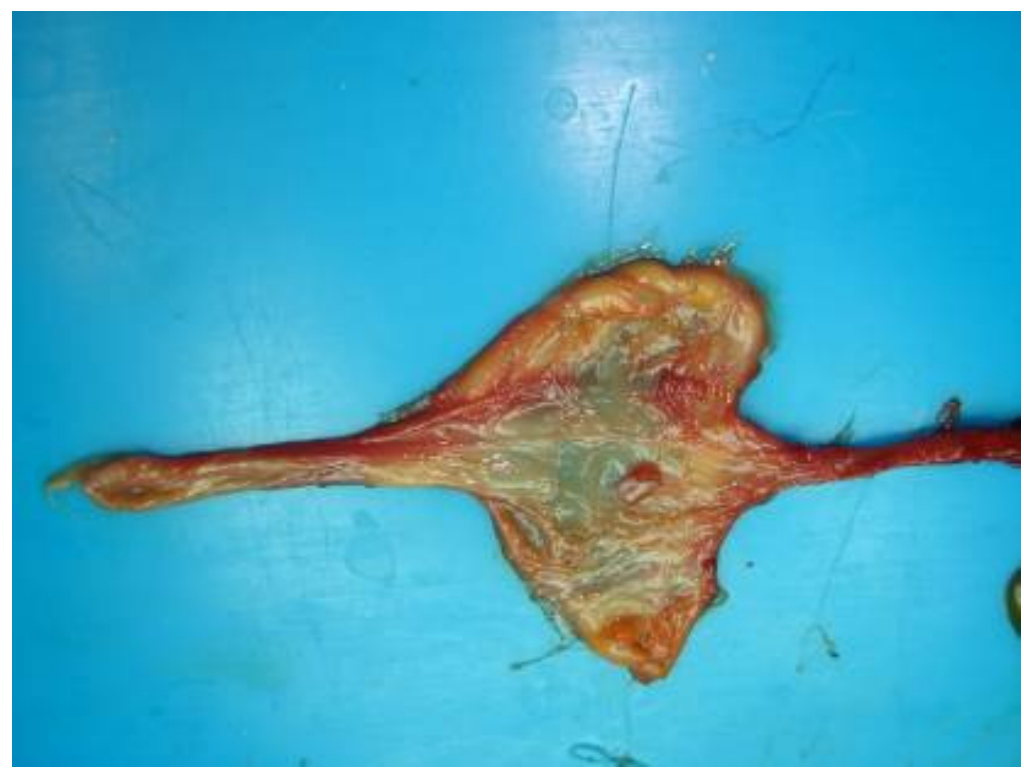

Figura 5: Inglúvio de pombo-doméstico

\section{DISCUSSÃO}

Segundo Nickel, Schummer e Seiferle (1977) a porção cervical do esôfago é mais longa que a torácica, característica anatômica observada em todas as espécies estudadas.

Em nenhuma das ordens estudadas o esôfago cervical segue pela linha média do pescoço desviando-se caudalmente para o lado direito, como relatou Nickel, Schummer e Seiferle (1977) e Getty (1986) e nem posicionado ventralmente à traquéia (GETTY, 1986), inicia-se na face ventral do pescoço e logo no início do mesmo desvia-se para o antímero direito, antagonicamente à traquéia concordando com Dyce, Sack e Wensing (1997).

O esôfago dilata-se formando o inglúvio, que está posicionado ventrolateralmente e cranialmente aos músculos peitorais, conforme relatou 
SANTOS, A.L.Q. et al. Estudo anatômico comparativo do tubo digestório de aves da ordem Columbiformes. PUBVET, Londrina, V. 6, N. 10, Ed. 197, Art. 1323, 2012.

Getty (1986), é particularmente grande, esférico (NICKEL; SCHUMMER; SEIFERLE, 1977), forma uma bolsa fora do esôfago e não duas, como afirma Duke (1996), já que não existe nenhum tipo de divisão interna.

Conforme Nickel,; Schummer e Seiferle (1977), o esôfago torácico estende-se dorsalmente á traquéia, entre a siringe e a superfície ventral do pulmão até a base do coração e superfície dorsal do fígado coincidindo com nossos resultados. Segundo Getty (1986), o esôfago torácico segue até a face medial do lobo hepático esquerdo.

O estômago é dividido em proventrículo e ventrículo (NICKEL; SCHUMMER; SEIFERLE，1977, MACARI; FURLAN; NAKAGHI，1994, BENNETT; DEEM, 1996), os quais são anatomicamente e fisiologicamente distintos (NICKEL; SCHUMMER; SEIFERLE, 1977).

O proventrículo é pequeno e situa-se cranialmente ao grande ventrículo, separado do mesmo por uma distinta constricção, o istmo, como descreveu Getty (1986). O estômago químico apresenta-se em posição paramediana esquerda, no terço médio da cavidade toracoabdominal, e não no quadrante inferior esquerdo como relatou Getty (1986). Observou-se uma relação do proventrículo com a face ventral do lobo hepático esquerdo em todas as espécies, concordando com o citado por esse autor.

O estômago muscular possui formato arredondado, e é bem desenvolvido, justificando a observação feita por Duke (1996) e Bennett e Deem (1996), que afirmam ser o ventrículo altamente especializado em espécies que se nutrem de alimentos duros. Em todas as espécies, o diâmetro do seu eixo craniocaudal é maior que o dorsoventral, conforme relata Getty (1986). A face ventral do estômago muscular relaciona-se à superfície dorsal do lobo hepático esquerdo e em parte ao lóbulo direito como o descrito por Nickel, Schummer e Seiferle (1977).

O duodeno é o segmento mais ventral do intestino, emerge da face dorsal do ventrículo, segue caudoventralmente em sua maior parte do lado direito e dorsalmente ao lobo hepático direito, apenas através de sua porção 
SANTOS, A.L.Q. et al. Estudo anatômico comparativo do tubo digestório de aves da ordem Columbiformes. PUBVET, Londrina, V. 6, N. 10, Ed. 197, Art. 1323, 2012.

cranial, concordando em parte com a afirmação de Nickel, Schummer e Seiferle (1977) e Deem e Bennett (1996).

A união da porção descendente com a porção ascendente do duodeno ocorre a nível do terço final do coloreto, ventralmente a este, conforme já descrito por Getty (1986).

A alça ascendente do duodeno dispõe-se lateralmente à face direita da alça descendente do duodeno, mantendo contato com parte do segmento jejunoilíaco e parte do coloreto, relaciona-se à superfície dorsal do fígado, testículo direito ou ovário, de acordo com a citação de Nickel, Schummer e Seiferle (1977).

Nickel, Schummer e Seiferle (1977) relatam que a união entre o duodeno e jejuno-íleo ocorre ao nível do lobo renal cranial direito, igualmente ao observado neste estudo.

O intestino delgado é dividido em três segmentos distintos, denominados duodeno, jejuno e íleo por Deem e Bennett (1996), Dyce, Sack e Wensing (1997), Getty (1986), Nickel, Schummer e Seiferle (1977), Andrade et al. (2004) e Borges et al. (2004). Ao contrário, este estudo considera apenas dois segmentos distintos denominados duodeno e jejuno-íleo, assim como Souza et al. (2005).

O segmento jejunoilíaco forma alças dispostas em "U" em todas as ordens, concordando com Deem e Bennett (1996). Estão dispostas uma sobre a outra, predominantemente no antímero direito da cavidade, como cita Dyce, Sack e Wensing (1997).

É o segmento intestinal mais longo estudado, conforme o exposto por Nickel, Schummer e Seiferle (1977). Situa-se ventralmente aos rins e dorsalmente ao duodeno e estômago muscular concordando em parte com Getty (1986).

O intestino grosso compreende um par de cecos e o cólon, são realmente muito curtos e localizam-se na junção dos intestinos delgado e grosso como relatam Nickel, Schummer e Seiferle (1977); Dyce, Sack e Wensing (1997) e Duke (1996). 
SANTOS, A.L.Q. et al. Estudo anatômico comparativo do tubo digestório de aves da ordem Columbiformes. PUBVET, Londrina, V. 6, N. 10, Ed. 197, Art. 1323, 2012.

Coloreto foi o termo utilizado para denominar o último segmento intestinal, diferindo de Nickel, Schummer e Seiferle (1977) que utiliza "cólon" e Getty (1986) Schwarze (1980), que optaram por "reto". Estende-se da união ileocecal à cloaca, nas aves providas de ceco, assim como relata Deem e Bennett (1996) e localiza-se na parte dorsal do quadrante caudal esquerdo da cavidade celômica, como cita este mesmo autor.

\section{CONCLUSÕES}

Conclui-se que as aves da ordem Columbiformes estudadas apresentam inglúvio e cecos, e o tubo digestório possui poucas variações topográficas entre elas.

\section{REFERÊNCIAS}

ANDRADE, M. B.; SANTOS, A. L. Q.; CARVALHO, S. F. M.; BORGES, K. M.; OLEGÁRIO, M. M. M.; DIAS, E. A.; PEREIRA, R. V. V.; PEREIRA, P. C.; MIRANDA, R. L.; SILVA, C. B.; CASTRO, J. B.; ANDRADE, T. D.; COLICHINI, P. A. Descrição anatômica do tudo digestivo de Agapornis personata fischeri (PSITTACIDAE). In: ENCONTRO DE CIÊNCIAS AVÍCOLAS, 7., 2004, Uberlândia. Anais... Uberlândia: UFU. 2004, p. 13.

ANDRADE, M. B.; BORGES, K. M.; SANTOS, A. L. Q.; OlEGÁRIO, M. M. M.; SILVA, C. B.; PEREIRA, P. C.; DIAS, E. A.; PEREIRA, R. V. V.; DIAS, T. A.; CASTRO, J. B.; CARVALHO, S. F. M.; MIRANDA, R. L.; COLICHINI, P. A. Aspectos anatômicos do tubo digestivo de periquitoestrela (Aratinga aurea - GMELIN, 1788) (PSITTACIDAE). In: ENCONTRO DE CIÊNCIAS AVÍCOLAS, 7., 2004, Uberlândia. Anais... Uberlândia: UFU, 2004. p. 01.

BENNETT AVERY, R.; DEEM, S. L. O sistema gastrointestinal das aves: I. Compêndio de Educação Continuada - para o Médico Veterinário, Florida, v. 1, n. 1, p. 50-56, outono 1996.

BORGES, K. M.; ANDRADE, M. B.; OLEGÁRIO, M. M. M.; SILVA, C. B.; CASTRO, J. B.; CARVALHO, S. F. M.; SANTOS, A. L. Q. Descrição anatômica do tubo digestivo de frangod'água-azul (Porphyrula martinica - LINNAEUS, 1776). In: SEMANA ACADÊMICA DA UNIVERSIDADE FEDERAL DE UBERLÂNDIA, 1., 2004, Uberlândia. Anais... Uberlândia: UFU, 2004. 1CD-Rom.

COMITÊ BRASILEIRO DE REGISTROS ORNITOLÓGICOS Listas das aves do Brasil. 10a Edição. Versão 25/1/2011. Disponível em <http://www.cbro.org.br>. Acesso em: 20 jan. 2011.

DEEM, S. L.; BENNETT AVERY, R. O sistema gastrointestinal das Aves: II. Compêndio de Educação Continuada - para o Médico Veterinário, Florida, v. 1, n. 2, p. 118-123, inverno 1996. 
DYCE, K. M.; SACK, W. O.; WENSING, C. J. G. Tratado de anatomia veterinária. 2 ed. Rio de Janeiro: Guanabara Koogan, 1997. 663 p.

DUKE, G. E. Digestão nas aves. In: DUKES, H. H. Dukes/Fisiologia dos animais domésticos. 11 ed. Rio de Janeiro: Guanabara Koogan, 1996. p. 390-397.

FLÔRES, M. L. et al. Surto de megabacteriose em canários-belgas (Serinus canária) em um criatório no estado do Rio Grande do Sul: relato de caso. Clínica Veterinária, São Paulo, v. 10, n. 54, p. 24-26, jan/fev. 2005.

GETTY, R. SISSON/ GROSSMAN: Anatomia dos animais domésticos. 5 ed. Rio de Janeiro: Guanabara Koogan, 1986.

KING, A.S.; McLELLAND, J. Birds: Their Structure and Function. 2ed. Londres: Baillière Tindall, 1984.

LEMOS, M. et al. Salmonella em aves silvestres no Jardim Zoológico do Rio de Janeiro, RJ. Revista Brasileira de Ciência Veterinária, Niterói, v. 6, n. 1, p. 40-43, jan/abr. 1999.

MAPELI, E. B. Sistemática e parâmetros epidemiológicos de helmintos parasitos de jaós (Crypturellus undulatus), no estado do Mato Grosso do Sul (Pantanal de Paiaguás), e de codornas (Nothura maculosa) e nambuzinhos (Crypturellus parvirostris) no estado de São Paulo, 2003. 84 f. Dissertação (Doutorado) - Faculdade de Ciências Agrárias e Veterinárias, Universidade Estadual Paulista, Jaboticabal, 2003.

MARÇAL Jr., O. M.; FRANCHIN, A. G. Aves, do latim Avis. In: DEL-CLARO, K.; PREZOTO, F. As distintas faces do comportamento animal. Jundiaí: Livraria Conceito, 2003. p. 105-119

MCLELLAND, J. Sistema digestivo das aves. In: GETTY, R. Sisson/Grossman: anatomia dos animais domésticos. $5^{\circ}$ ed. Rio de Janeiro: Guanabara Koogan, 1986. p. 1445-1464.

NICKEL, R.; SCHUMMER, A.; SEIFERLE, E. Anatomy of the domestic birds. Berlim: Hamburger, Verlag, 1977.

PERRINS, C.M. The New Encyclopedia of Birds. Oxford: Oxford University Press, 2004.

PETERSON, R. T. et.al. As aves. Rio de Janeiro: J. Olympio, 1971. 208 p.

POUGH, F. H.; HEISER, J. B.; McFARLAND, W. N. Características das aves: especializações para o vôo. In: . A vida dos vertebrados. 2 ed. São Paulo: Atheneu, 1999. cap. 17, p. 521-552.

SCHWARZE, E. Compêndio de anatomia veterinária - anatomia de las aves. Zaragoza: Acribia, 1980. 212 p.

SICK, H. Ornitologia brasileira. Rio de Janeiro: Nova Fronteira, 1997. 862 p.

SOUZA, A. G.; BORGES, K. M.; OLEGÁRIO, M. M. M.; ANDRADE, M. B.; PEREIRA, P. C.; SANTOS, A. L. Q.; VIEIRA, L. G. Descrição anatômica do tudo digestivo de periquitoaustraliano-azul (Melopsittacus undulatus). (FRINGILLIDAE). In: ENCONTRO SOBRE ANIMAIS SELVAGENS - MANEJO E CONSERVAÇÃO, 3., 2005, Uberlândia. Resumos... Uberlândia: Universidade Federal de Uberlândia, 2005. 